\title{
A socio-economic survey of pangolin hunting in Assam, Northeast India
}

\author{
Neil D’Cruze', Bhagat Singh', Aniruddha Mookerjee', Lauren A. Harrington², \\ David W. Macdonald ${ }^{2}$
}

I World Animal Protection, 222 Grays Inn Rd., London WC1X 8HB, UK 2 Wildlife Conservation Research Unit, Department of Zoology, University of Oxford, Recanati-Kaplan Centre, Tubney House, Abingdon Road, Tubney, Abingdon OX13 5QL, UK

Corresponding author: Neil D’Cruze (neil.dcruze@zoo.ox.ac.uk)

Academic editor: T. Ziegler | Received 13 June 2018 | Accepted 12 October 2018 | Published 3 December 2018

http://zoobank.org/AC5565D8-B812-450D-944C-980F91A07FF8

Citation: D'Cruze N, Singh B, Mookerjee A, Harrington LA, Macdonald DW (2018) A socio-economic survey of pangolin hunting in Assam, Northeast India. Nature Conservation 30: 83-105. https://doi.org/10.3897/ natureconservation.30.27379

\begin{abstract}
India has been identified as a source country for the illegal international trade in endangered pangolins, "scaly mammalian anteaters", widely considered as the "world's most trafficked mammal". In this study, we investigated the involvement of hunters belonging principally to three locally prominent tribes (Biate, Dimasa and Karbi) in Assam State, Northeast India. Based on the results of interviews with 141 individuals, we conclude that all three tribal groups engaged in pangolin hunting between 2011 and 2016. Although pangolin meat is used locally, we found that hunters largely targeted pangolins for their scales and that substantial commercial gain via urban middlemen has now supplanted low-level traditional use as the primary driver for this activity. On average, each hunter captured one pangolin per year with the potential to earn 9,000 INR (135 USD) for a single animal (equating to approximately four months average income). The majority of hunters (89\%) stated that pangolins were less abundant than they were five years ago, which suggests off-take is unsustainable. All hunters interviewed appeared to hunt pangolins occasionally, regardless of tribe, demography or income, which suggests that any mitigation strategy should focus on rural hunters. Whilst interventions to reduce poverty are no doubt required, we argue that such interventions alone are unlikely to be effective in reducing pangolin hunting. Rather, there is a need for co-ordinated packages of mutually reinforcing interventions to address this pangolin hunting in a more comprehensive manner. In particular, implementing a demand reduction strategy targeting urban consumers is urgently required.
\end{abstract}

\section{Keywords}

Bushmeat, Manis crassicaudata, Manis pentadactyla, traditional medicine, wildlife trade

Copyright Neil D'Cruze et al. This is an open access article distributed under the terms of the Creative Commons Attribution License (CC BY 4.0), which permits unrestricted use, distribution, and reproduction in any medium, provided the original author and source are credited. 


\section{Introduction}

Pangolins ("scaly mammalian anteaters", belonging to the order Pholidota) are extensively hunted for their meat and for their scales (Baillie et al. 2014). Pangolin meat is considered a delicacy in some countries [notably in China and Vietnam (Challender 2011, Challender et al. 2015, Cheng et al. 2017)] and believed in some cultures to have health benefits [e.g. in eastern Nepal (Katuwal et al. 2015) and parts of India (Mohapatra et al. 2015, Aisher 2016 and references therein)]. Pangolin scales are used in Traditional Medicine, predominantly in China and Vietnam (Challender 2011, Challender et al. 2015, Xu et al. 2016), but also traditionally, amongst rural people, across South and Southeast Asia (e.g. Misra and Hanfee 2000, Katuwal et al. 2015, Aisher 2016) and Africa (Boakye et al. 2014, 2015, Soewu and Ayodele 2009, Soewu and Adekanola 2011, Soewu and Sodeinde 2015) although no reliable clinical efficacy of scales has been reported (Cheng et al. 2017). Pangolin scales are also used in rituals and as decorative items amongst local communities (e.g. Mahmood et al. 2012, Mohapatra et al. 2015). Ten years ago, relatively few people knew what a pangolin was (Zhang et al. 2017) but in recent years they have become an icon of the illegal wildlife trade in the media (Harrington et al. 2018) and are now widely reported to be the "world's most heavily trafficked mammal" (Sutter 2014, Aisher 2016).

The true extent of the numbers of pangolins hunted throughout their range is unknown, but it has been estimated that over a million individuals were taken from the wild between 2000 and 2013 (Challender et al. 2014a). Between 2010 and 2015, 1,270 reported seizures, in 67 countries and territories across six continents, involved a total of 120 tonnes in body parts, whole animals and scales of pangolins, plus an additional 46,000 individual pangolins (Heinrich et al. 2017) and this is believed to represent only the "tip of the iceberg" (Challender et al. 2015). As such, when key aspects of their biology [low reproductive output (e.g. Mahmood et al. 2015, Zhang et al. 2016), low density (e.g. Mahmood et al. 2014, 2018) and specialised niche requirements (Ma et al. 2017)] are also taken into account, the international trade of pangolins is now recognised as the most significant impediment for their conservation (Zhang et al. 2017).

There has been a notable shift in the sourcing of pangolins for the Chinese market, to other Manis species in Southeast Asia [predominantly Malaysia and Indonesia (Pantel and Chin 2008, Pantel and Anak 2010, Challender 2011, Gomez et al. 2017)]. A zero export quota for commercial trade in Asian species in 2000 (CITES 2017) led to a shift to target African species [Phataginus and Smutsia spp. (Challender 2011, Challender and Hywood 2012, Mambeya et al. 2018, Gomez et al. 2016, Heinrich et al. 2016, Ingram et al. 2017)]. In addition, it has also become clear that pangolins in other range states such as India (Mohapatra et al. 2015, Choudhary et al. 2018), Nepal (Katuwal et al. 2015, Thapa et al. 2014), Pakistan (Mahmood et al. 2017), Bangladesh (Trageser et al. 2017) and Myanmar (Zhang et al. 2017) are also being targeted by actors involved in the illegal international trade in these species. As such, all eight 
pangolin species are now listed as threatened on the IUCN Red List of Threatened Species (www.redlist.org) and, whilst the initial post-2000 trade from Africa was legal under CITES permits (CITES 2017), since 2016 (effective as of January 2017), all international commercial trade in wild-caught pangolins has been banned under their CITES Appendix I listing at the CITES Conference of the Parties 17 (https://cites. org/eng/app/appendices.php).

Understanding the scale and type of use of wildlife products, the drivers of commercial trade and what motivates people to hunt illegally, is crucial for developing effective interventions (TRAFFIC 2008, Duffy and St John 2013, Duffy et al. 2016, Nash et al. 2016). In the case of pangolins, the drivers of trade at a global scale are relatively well known (Heinrich et al. 2017). In contrast, information on what drives local people to hunt pangolins, and how this is connected with traditional cultural use, seems to be lacking for some communities. Local studies of pangolin hunting and trade (at the supply end of trade) have typically focused on market surveys (e.g. Nijman et al. 2016, Ingram et al. 2017), seizure data (e.g. Mohapatra et al. 2015, Nijman 2015, Cheng et al. 2017, Gomez et al. 2016, 2017) or questionnaires seeking local perceptions of hunting or trade activities (e.g. Katuwal et al. 2015, Nash et al. 2016, Zhang et al. 2017) rather than asking hunters directly about their own activities and beliefs. In Asia, exceptions are: Nash et al. (2016) who assessed local ecological knowledge across seven protected areas in Hainan, China; Zhang et al. (2017) who gathered data from 38 informants in the northwest of Kachin State, Myanmar; Mahmood et al. (2017) who interviewed an unreported number of local people in Pakistan; and Pantel and Anak (2010) who interviewed 13 individuals in Sabah, Malaysia.

Here, we present detailed data on the hunting activities of 141 male rural hunters, belonging to three local tribes (Biate, Karbi and Dimasa), living in the least populated district of Assam (Dima Hasao), located in Northeast India. The aim of our study was to: (1) quantify the extent to which local hunters hunt pangolins in this previously unstudied area; (2) describe the circumstances under which they hunt pangolins; and (3) their reasons for doing so. Ultimately, we aimed to identify what a pangolin is worth to a rural hunter in this region and thus to understand the drivers for such hunting activity, with a view to considering the nature and magnitude of intervention that might be required to reduce it.

Two species of pangolin, the Indian pangolin (Manis crassicaudata) and the Chinese pangolin ( $M$. pentadactyla) currently occur in Northeast India. Both species are solitary, primarily nocturnal (sometimes crepuscular) and largely terrestrial (digging their own burrows) although they are fully capable of climbing trees (Baillie et al. 2014, Challender et al. 2014b). There is almost no information available on the population status of these two pangolin species at a local level in India; however, globally, populations are considered to be in significant decline and therefore the Indian pangolin is currently classified as Endangered and the Chinese pangolin as Critically Endangered, according to the IUCN Red List of Threatened Species (Baillie et al. 2014, Challender et al. 2014b). 


\section{Methods}

\section{Study area}

Known as the "Gateway of Northeast India", Assam State comprises approximately $12.8 \%$ of the total tribal population of India (Census of India 2011). The Dima Hasao district (located at $92^{\circ} 37-93^{\circ} 17 \mathrm{E}, 25^{\circ} 3-25^{\circ} 27 \mathrm{~N}$, Fig. 1) covers an area of $4,890 \mathrm{~km}^{2}$ and is inhabited by more than 12 ethnic tribes (including the Biate, Dimasa, Hmar, Hrangkhol, Jaintia, Karbi, Khelma, Kuki, Lushai, Rongmei, Vaiphei and Zeme) in addition to several other non-tribal groups (including Assamese, Bengali and Nepali communities). The physical geography of the region includes a mix of tropical semi-evergreen forests, tropical deciduous forests, secondary forests and crop fields (Choudhury 2013). It is the least populated district of Assam [with a population of 213,529 and a population density of 44 individuals per $\mathrm{km}^{2}$ (Census of India 2011)], with most of the villages situated far from modern conveniences and inaccessible by road or rail (Betlu 2013).

Our study focussed on three of the predominant indigenous tribes of Assam State in Northeast India: (1) Biate; (2) Dimasa; and (3) Karbi. These tribes are characterised by unique traditions and cultures distinct from each other and from other ethnic groups of the region (Teronpi et al. 2012). However, broadly speaking, subsistence agriculture or hunting and gathering are practised by rural villagers belonging to all three groups (Sajem and Gosai 2006). A deep faith in, and preference for, their traditional healthcare system (based on surrounding flora and fauna) rather than the modern system of medicine has been reported across all three groups (e.g. Sajem and Gosai 2010, Teronpi et al. 2012, Betlu 2013). Similarly, although they are known to practise traditional religion (that is animistic in nature) to varying degrees, the prevalence of associated rituals has been affected by the advent of Christianity across all three groups (e.g. Sajem and Gosai 2010, Teronpi et al. 2012, Betlu 2013).

With regards to national legislation, selling pangolins for commercial gain in India is illegal under Schedule I of the Wildlife (Protection) Act 1972. However, it is important to note that hunting pangolins outside of Reserved Forests (i.e. protected areas) for personal use is sometimes permitted for certain native tribal communities (Aiyadurai 2011). Specifically, the state of Assam has several tribal majority areas recognised as Autonomous regions governed by laws framed by Regional Councils according to Schedule 6 of the Indian Constitution. As such, hunting of pangolins by Biate, Dimasa and Karbi tribal communities for personal use outside of Reserved Forests in areas of Dima Hasao district is technically permissible assuming: (1) there is no contravening law made by the Regional Council on hunting; (2) the Council's law prevails over the State's law; and (3) the State Governor has not passed any law to restrict any hunting (Government of India 2007). Nevertheless, the State Governor has the power to amend the laws of the Regional Council in any situation where conflict should occur (Government of India 2007). 


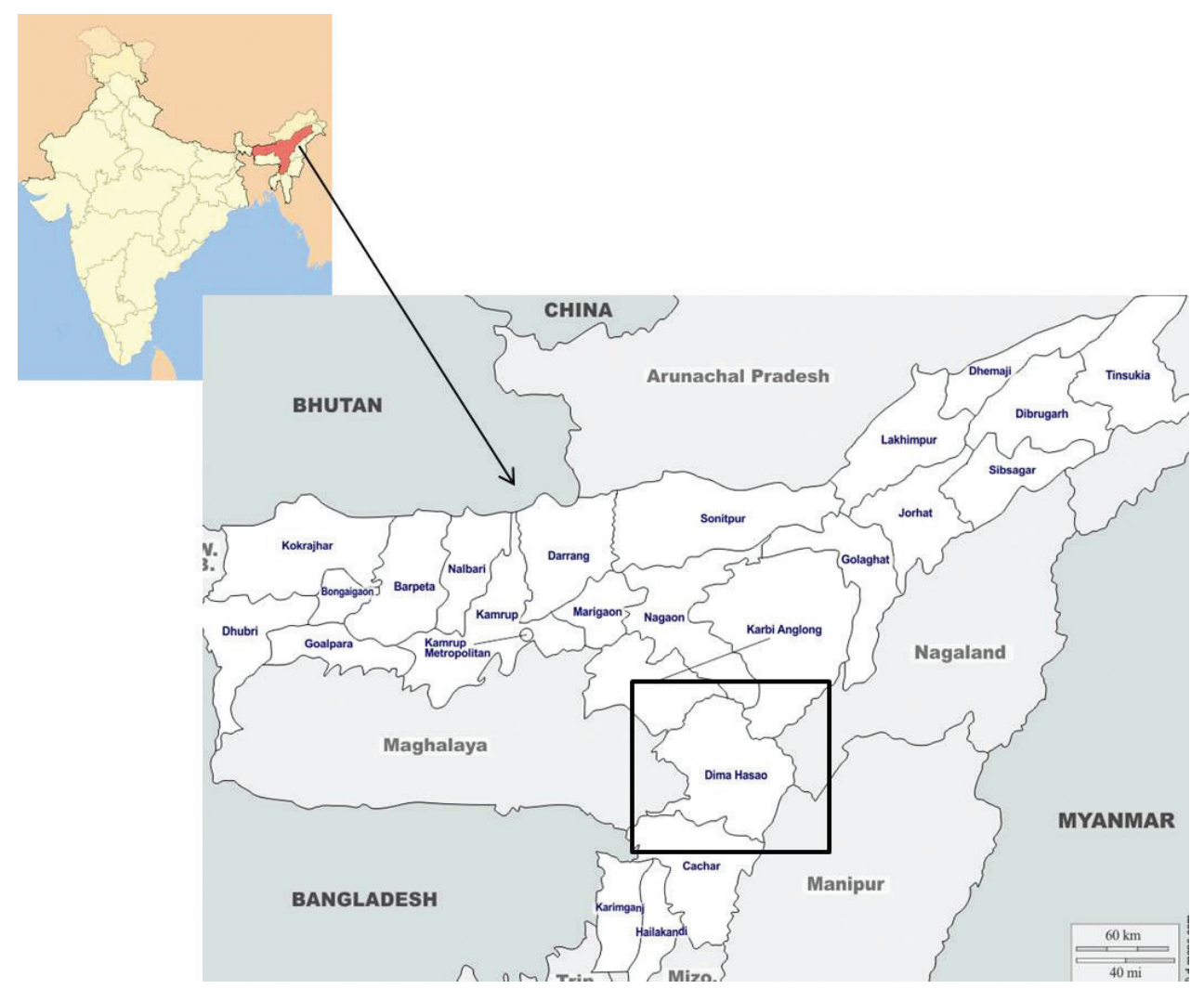

Figure I. Location of the Dima Hasao district in Northeast India. India map by Ganeshk (own work derived from Image: India-locator-map-blank.svg, CC BY-SA 3.0, https://commons.wikimedia.org/w/ index.php?curid=801542). State map from d-maps.com (http://d-maps.com/m/asia/india/assam).

\section{Data collection}

We used semi-structured interviews for which participants were purposefully selected rather than randomly sampled. The questionnaire focused on meat consumption of hunters, pangolin hunting and attitudes towards pangolins. Key questions were related to personal and commercial use of both the meat and scales of hunted pangolins and, specifically, whether and where they were sold and for how much. We interviewed hunters in villages that self-identified as having hunted a pangolin and that were willing to participate in the study, through a process of chain referral (Newing 2011), whereby participants recommended other potential participants or persuaded others to take part. This snowball sampling approach (Babbie 2004) is useful when researchers are interested in the opinions of a particular hidden population (Potgieter et al. 2017) and, in this case, ensured that participants who could provide information pertinent to the study were selected as representatives of the pangolin hunting community. Our aim was not to extrapolate our results to the wider community but to understand what drives the hunters whom we interviewed to hunt pangolins. 
Interviews were conducted by four local field staff asking a set of predetermined questions that included open-ended, closed and multiple choice questions (see Suppl. materials 1). Participants were initially asked some non-pangolin related questions (including what pets they kept) and what type of meat they preferred to eat before being asked about their use of pangolins; by asking sensitive questions at the end of the interview, our aim was to ensure that respondents were as comfortable and as relaxed as they could be (Newing 2011). Interviews were conducted in Hindi, Biate, Dimasa and Karbi and later translated into English. Surveys were carried out in 31 villages in the Dima Hasao district of Assam, between January and October 2017. In accordance with the British Sociological Association Statement of Ethical Practice (BSA 2017), informed consent was obtained verbally from every survey participant prior to the interview, participants were made aware of their rights to voluntarily participate or to decline, no identifying participant or household data were collected and the database collated was entirely anonymous. In addition, villages were coded in the database and village names not reported to further protect study participants from harm or discrimination (St John et al. 2016).

\section{Data analysis}

We used descriptive statistics to describe patterns and trends in the data and used chisquared tests of association and non-parametric statistical tests to test for relationships between and differences in demographic and hunting parameters and amongst hunters of different ethnicity. For chi-square tests, we obtained simulated $p$ values (based on 2000 replicates) for tests with low expected values. All statistical analyses were carried out in R (version 3.3.3, R Core Team 2017). Pairwise post hoc chi-squared tests were performed with the package fifer (Fife 2017), $p$ values adjusted for multiple comparisons. All interviews were included in the analysis, even if they contained missing data, but some questions were omitted due to overlap and/or potential misinterpretation by participants.

\section{Results}

Interviews lasted between 30 minutes and two and a half hours. Individual questions were answered by between $57 \%$ and $>90 \%$ of interviewees. All interviewees had captured at least one pangolin in the last five years. Some of the hunters interviewed took part in the same hunt, therefore the numbers reported do not represent the number of individual pangolins taken during the study, rather they represent the individual hunters that took part in these activities. Similarly, hunters did not distinguish between pangolin species so data refer collectively to "pangolins". 


\section{Hunter demographics}

Interviewees, on average, were in their 30s (median age $=36$, range 17-76), owned one or two houses $[N=4(2.8 \%)$ owned three], with four to seven people per household (median $=6$, range $1-12$ ) including two to three children (median $=2$, maximum $=8)$. Ninety percent $(N=102)$ were married. All but three interviewees were originally from the area and all but four belonged to either the Biate $(N=82)$, Dimasa $(N=33)$ or Karbi $(N=22)$ tribes (one belonged to the Nepali community and another to the Khasi tribe in the neighbouring state of Meghalaya, two were of unknown affiliation). Dimasa were all Hindu (as was the single Nepali), Biate (with the exception of one Hindu), Karbi and the Kashi were Christian (one Karbi described himself as animist). With the exception of education level and income (below), there were no apparent demographic differences amongst tribal/community members interviewed.

Education level of interviewees was variable: $53.2 \%(N=75)$ went to middle/high school, but only $10 \%(N=7)$ of those completed $10^{\text {th }}$ class $\left(10^{\text {th }}\right.$ grade in US or Year 11 in the UK); $19.9 \%(N=28)$ had no education and none was educated at or beyond senior secondary school ( $12^{\text {th }}$ grade in US or A levels in UK). Interviewees with no, or only primary, education, were older than those who attended middle or high school $\left(\mathrm{K}-\mathrm{W} \chi^{2}=12.38, \mathrm{DF}=4, p=0.015\right)$ and Biate were significantly better educated than either Dimasa or Karbi [see Table 1; there were no differences in age amongst members of each tribe $\left.\left(\mathrm{K}-\mathrm{W} \chi^{2}=3.93, \mathrm{DF}=3, p=0.269\right)\right]$.

With the exception of one individual [who earned an estimated 300,000 INR (Indian Rupees), 4,644 USD, per year], all interviewees described themselves as farmers, farmers/labourers, or farmers/hunters/labourers, with an estimated annual household income of between 10,000 and 90,000 INR (median = 25,000 INR, or 387 USD; $1 \mathrm{USD}=64.6 \mathrm{INR}, 23 / 11 / 17$ ). Dimasa reported significantly higher average incomes than did members of the other two tribes but there was considerable variation within tribes and overlap amongst them (Table 1).

Table I. Differences in education and reported income amongst the three tribes.

\begin{tabular}{|c|c|c|c|c|c|}
\hline & \multicolumn{3}{|c|}{ Ethnicity/tribe } & \multirow{2}{*}{ Statistics } & \multirow[b]{2}{*}{$p$} \\
\hline & Biate & Dimasa & Karbi & & \\
\hline Education & & & & $\chi^{2}=21.79 \mathrm{DF}=6$ & $0.002 *$ \\
\hline - Attended high school & $33 \%$ & $18 \%$ & $5 \%$ & Biate vs. Dimasa & $0.005^{\dagger}$ \\
\hline - No school education & $10 \%$ & $42 \%$ & $27 \%$ & Biate vs. Karbi & $0.007^{\dagger}$ \\
\hline \multicolumn{6}{|l|}{ Annual income (INR) } \\
\hline - Median & 21,500 & 32,500 & 27,500 & $\mathrm{~K}-\mathrm{W} \chi^{2}=26.55 \mathrm{DF}=3$ & $<0.001$ \\
\hline - Maximum & 70,000 & 90,000 & 60,000 & & \\
\hline
\end{tabular}

${ }^{*}=$ Simulated $p$ value,${ }^{\dagger}=$ post hoc adjusted $p$ value. 


\section{Bush meat consumption}

Interviewees reported eating wild meat between one and five times per week (median $=1$, with no apparent difference amongst tribes; $\mathrm{K}-\mathrm{W} \chi^{2}=0.69, \mathrm{DF}=2, p=0.710$ ). Only $4.8 \%$ of interviewees relied primarily on wild meat $(73.6 \%$ supplemented domestic meat with wild meat). Only one interviewee listed pangolin as their favourite wild meat; most said that deer $(51.8 \%)$ or boar $(44.7 \%)$ were their favourite wild meat. Ranked by preference ( $\left(^{\text {st }}\right.$ to $\left.9^{\text {th }}\right), 89.4 \%$ of 85 respondents who included pangolin as a wild meat that they might consume, ranked them $4^{\text {th }}$ or lower and all respondents gave them low ranks significantly more often than either bear, bird, porcupine or primate (in addition to deer and boar that were most often ranked $1^{\text {st }}$ or $2^{\text {nd }}$; post hoc chi-squared tests, all $p=0.020$, with Bonferroni correction for 28 comparisons). Nevertheless, most interviewees said that when they did capture a pangolin, they ate it.

\section{Pangolin hunting}

Ninety-four percent $(N=133)$ of hunters described hunting pangolins as being dependent on finding field signs (footprints or marks in the mud or on the trees or fresh den holes). Field signs were sometimes detected opportunistically, when hunting in the forest for other animals or fishing. For example, one hunter remarked that (a pangolin hunt) was "not planned, if we see the pangolin footprints and new holes, then we change the plan and do a pangolin hunt". Sometimes pangolins were searched for deliberately. For example, one hunter described how five to six hunters spent several days systematically searching the forest for signs, another said that they "search every tree in the forest for fresh footprints" and another said "sometimes takes months to find them". It was not possible, however, to quantify from their descriptions of how they hunted pangolins to what extent either occurred. March to May was reported most frequently to be the best time for hunting pangolins (Fig. 2).

Hunters reported that pangolins were captured by being dug from their holes $(>2$ $m$ underground, usually with the help of several villagers or family members) or forced from tree holes with smoke or by cutting or burning down the tree. Escaping pangolins were picked up or caught with a spear. Only one hunter said that he used traps. Sometimes hunters accidentally came across pangolins in the open, in which case, when the animal rolled into a ball (documented defensive behaviour, Mohapatra and Panda 2014), they simply picked it up and put it in a bag. Pangolins captured alive were transported to hunters' homes in a bag and killed at home by "hitting on the head with knife" or by "cutting their head with a knife".

Frequency of hunting

Ninety-five percent $(N=134)$ of hunters reported hunting pangolins at least once in the last 12 months (median number of hunts in the last 12 months = 3, Fig. 3a). 


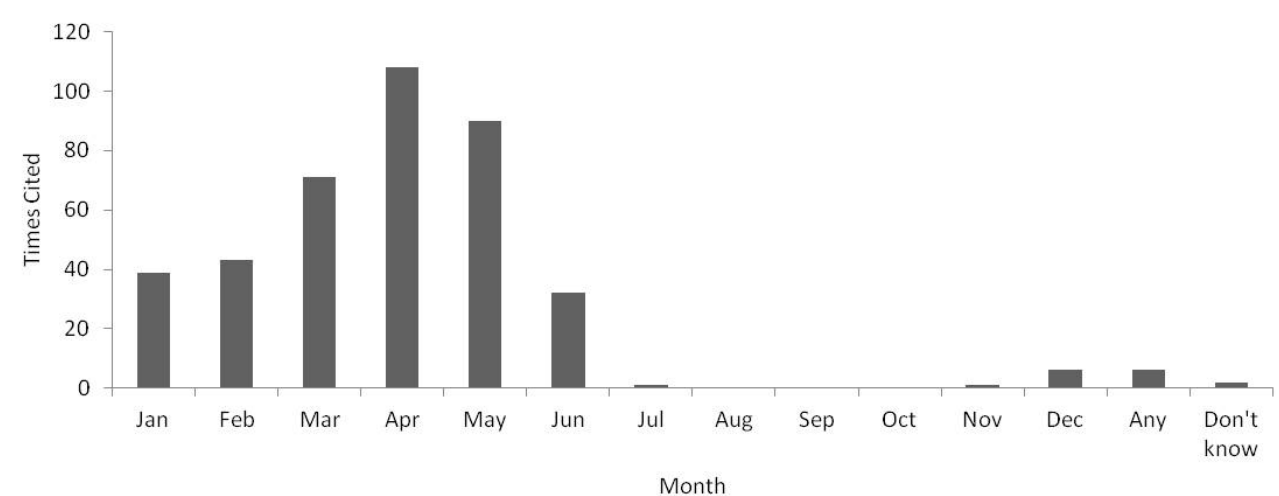

Figure 2. Reported best months for capturing pangolins (data are the number of times the month was cited). Note that most interviewees gave months as a range rather than a single optimal month so values sum up to more than the number of interviewees. Several hunters referred to signs being detectable "after the rain".
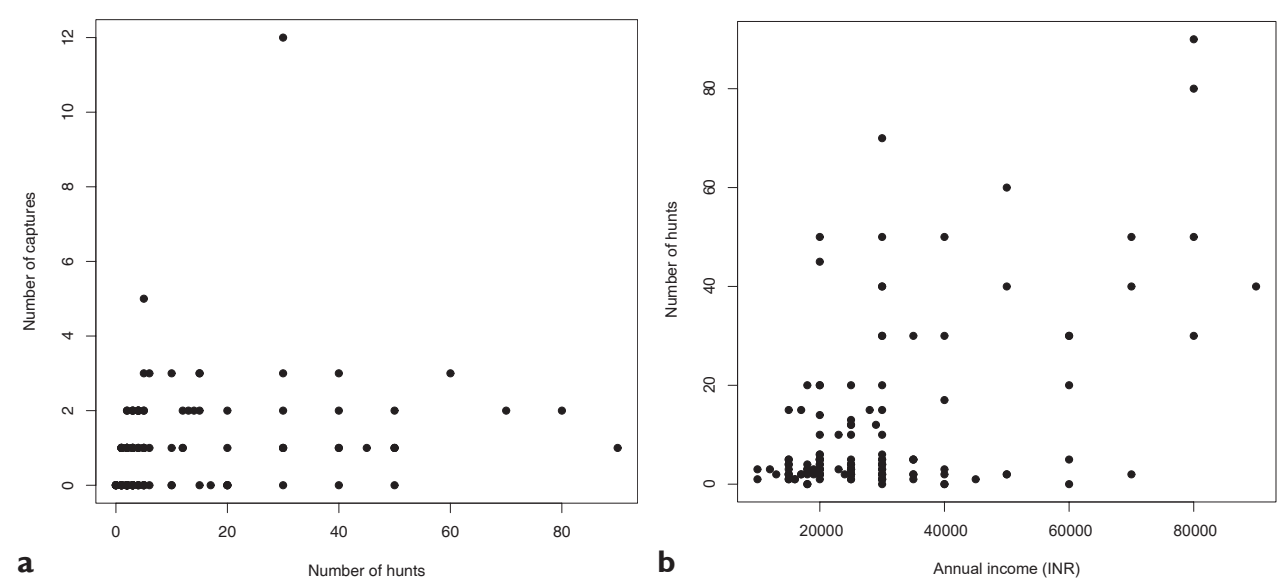

Figure 3. Reported number of pangolin captures in the last 12 months as related to reported number of hunts undertaken (a) $(r=0.418, p<0.001$; excluding the reported capture of 12 pangolins: $r=0.307, p$ $<0.001)$ and hunts in relation to reported annual income $(\mathbf{b})$.

Twenty-seven percent $(N=38)$ of hunters reported hunting pangolins 12 or more times (once per month or more) and 6.4\% $(N=9) 50$ or more times (approximately once per week, Fig. 3a).

\section{Hunting success}

Fifty-six percent $(N=79)$ of hunters stated that they had captured a pangolin at least once in the last 12 months (Fig. 3a). Individuals who had gone hunting frequently (at least once per month in the last 12 months) were more likely to have captured at least one pangolin in that time than those who had gone hunting infrequently: 
$73.7 \%$ of those that hunted $\geq 12$ times per year caught $\geq 1$ pangolin compared with $49.5 \%$ of those that hunted $<12$ times $\left(\chi^{2}=5.058, \mathrm{DF}=1, p=0.025\right)$. However, on average, the number of captures reported was low, regardless of the number of hunts undertaken (median number of captures in the last 12 months = 1, Fig. 3a). High capture rates were rare: only two interviewees reported capturing more than three pangolins in the last 12 months (Fig. 3a). Overall, the approximate average reported success rate (number of captures/number of hunts) per hunter was $21.6 \%$ but varied between 0 and $100 \%$.

Demographic and tribal differences in hunting behaviour

There was no apparent relationship between reported number of hunts or reported number of captures in the last 12 months and hunter age or household size (number of people in the house or number of children; all $r<0.2, p>0.05$ ). There was also no apparent difference in either hunts or captures amongst hunters of different tribes (hunts: K-W $\chi^{2}=$ $1.75, \mathrm{DF}=2, p=0.416$; captures: $\mathrm{K}-\mathrm{W} \chi^{2}=5.98, \mathrm{DF}=2, p=0.050$, excluding one high value of 12 pangolins reportedly captured by a Karbi hunter that we treated as an outlier - we suspected that this answer was not true and therefore did not include it in the analyses, see Fig. 3a). Across all hunters, there was a very weak positive correlation between the number of hunts undertaken and income $(r=0.297, p<0.001$; excluding the single high income of INR 300,000, Fig. 3b) but no such relationship for captures $(r<0.2, p>0.05)$.

\section{Drivers of pangolin hunting}

When asked how pangolins were prepared, all hunters interviewed reported that the pangolin bodies were boiled in hot water and that they removed the scales after boiling or described how boiling softened the skin rendering the scales easy to remove while retaining their original shape. Only two interviewees described the use of spices prior to serving the meat or sharing the meat amongst those involved in the hunt. With the exception of two apparently atypical interviewees (one older man who suggested that he had once captured a pangolin incidentally, cooked the meat and gave away the scales and an individual from outside the area, who said that he was dependent on wild meat and ate pangolin meat but did not use pangolins for commercial purposes), all hunters said yes to both questions when asked if they hunted pangolins for personal use and if they hunted pangolins for commercial use.

Pangolin meat

Most $(85.8 \%, N=121)$ hunters reported that they used pangolin meat for food, relatively few $(14.9 \%, N=21)$ reported using it for medicine (including $N=6$ who used it for both). One interviewee used the meat only for income; one said that they had no 

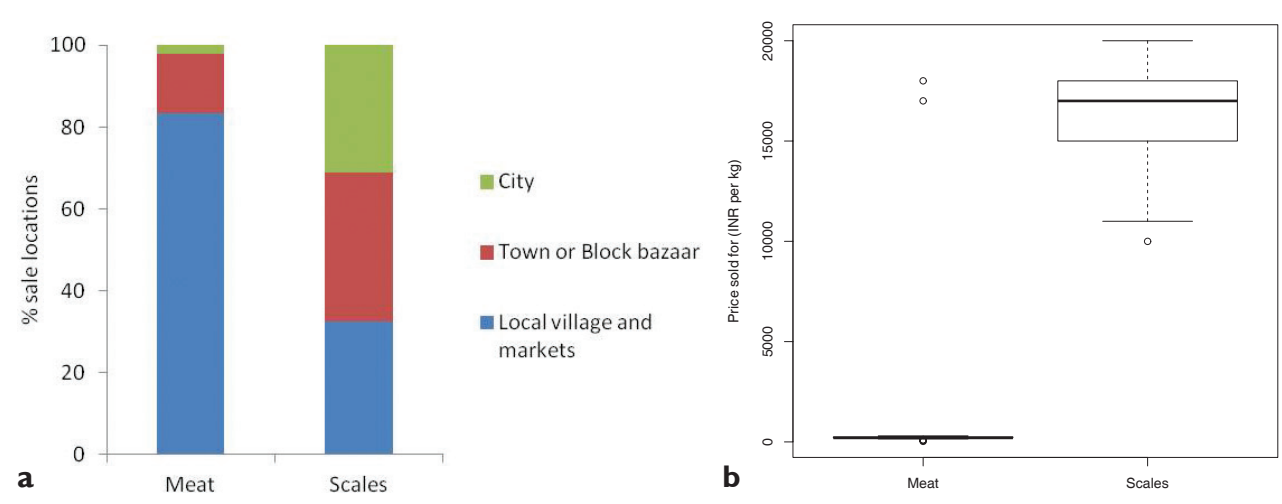

Figure 4. Sale locations (a) and price (b) for pangolin meat and scales as reported by interviewees $(N=90$ locations given by 61 hunters and $N=249$ locations given by 131 hunters, respectively, $N=81$ and 134 prices given). Local includes the village within which the hunter lives, surrounding villages and the local market (which moves within the local area amongst the villages); Town or Block bazaar includes towns (approximately 10-20 km away) and large markets (e.g. the Block bazaar serves the 'block', which is an administrative unit within the district); City refers to is a major urban centre (approximately $50 \mathrm{~km}$ away by road).

use for the meat. Precise medical uses were not specifically asked for, but interviewees reported usage for "piles", malaria, the "nervous system", stomach problems or (for pangolin liver specifically) "stomach disease".

Half ( $50 \%, N=71)$ of all hunters also sold the meat, mostly ( $83.3 \%$ locations) locally, in the village or at the local market (see Fig. 4a). With the exception of two interviewees who reported selling the liver and bile for medical purposes ("cancer medicine" and because it is "good for the nervous system") for 17,000 and 18,000 INR per kg (263 and 279 USD per kg, respectively), the price of meat per kg ranged between 80 and $300 \mathrm{INR}$ per $\mathrm{kg}(1.2-4.6 \mathrm{USD}$, median $=200 \mathrm{INR}$ or $3.1 \mathrm{USD}$ per $\mathrm{kg}, N=67$, Fig. 4b). There was some evidence that the Dimasa obtained higher prices for the meat (median 250 INR, 3.9 USD, per kg) than did the Biate or Karbi (median 200 INR, $3.1 \mathrm{USD}$, per kg, for both; $\left.\mathrm{K}-\mathrm{W} \chi^{2}=29.45, \mathrm{DF}=2, p<0.001\right)$. When asked what the meat that they sold would be used for, interviewees $(42.6 \%, N=60)$ listed a number of medical or health-related reasons, including the treatment of neurological disease, stomach ache and paralysis (liver and bile), use as massage oil, to "increase strength", "aid the digestive system" and that the liver and bile were "good for a weak person". One said that pangolin meat was "good for body, cure many diseases". Others thought that it would be used simply for food $(27.0 \%, N=38)$, did not know what it would be used for $(17.7 \%, N=25)$ or both $(1.4 \%, N=2)$.

\section{Pangolin scales}

Few $(12.1 \%, N=17)$ interviewees reported that they used the pangolin scales for medicine (those who gave precise medical uses referred only to "piles"); most ( $80.1 \%$, $N=113$ ) used them only for income (Fig 5a). Other minor uses included "protection 

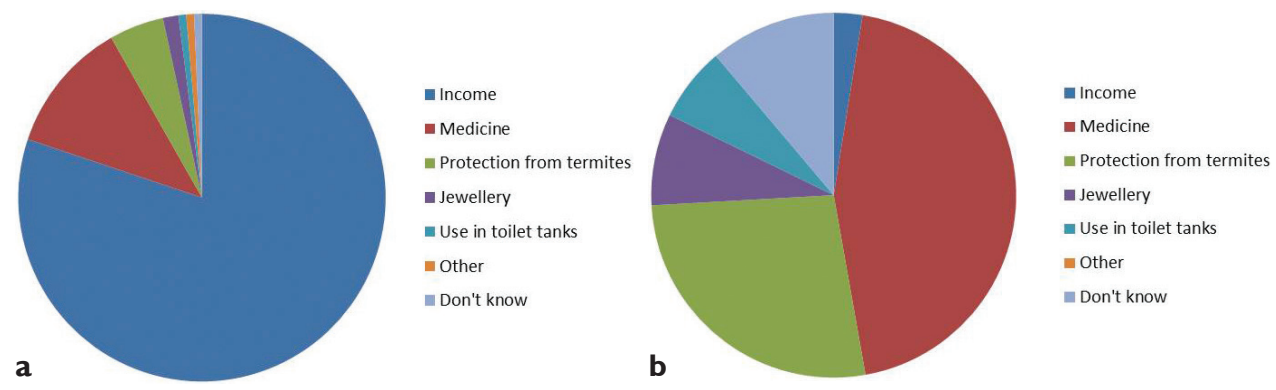

Figure 5. Percentage use of pangolin scales by interviewees (a) and buyers (as perceived by interviewees) (b) (note that interviewees listed up to four possible uses so the total number of uses was greater than the number of interviewees, $N=146$ and 197, respectively; percentages in the text refer to percentage of interviewees, $N=141$ ). Medicine refers almost exclusively to treatment for "piles" (see text), for which the prescribed use involved burning scales and inhaling (or squatting over) the smoke or boiling in water and drinking. "Protection from termites" referred to use in either houses or plantations and the belief that placing a scale under a pole or log would provide protection (four interviewees suggested that this was something that "older people" did). For perceived buyer uses, Jewellery was referred to exclusively as good luck charms or amulets, whereas interviewees referring to their own use used the term Jewellery without specifying any particular further purpose. "Use in toilet tanks" was explained as placing a scale/s in the toilet tank "to prevent it filling up too soon". Other = "protect house from fire" $(N=1)$.

from termites" $(N=7)$ and jewellery $(N=2$, see Fig 5a). Two said that they gave them away (most likely to other villagers).

Almost all $(96.5 \%, N=136)$ hunters sold the scales. Scales were more likely than meat to be sold in large markets, towns or the city $\left(\chi^{2}=70.97, \mathrm{DF}=2, p<0.001\right.$, Fig. 4a). The price of pangolin scales ranged between 10,000 and 20,000 INR per $\mathrm{kg}$ (median $=17,000 \mathrm{INR}, 263 \mathrm{USD}$, per $\mathrm{kg}, N=135$, Fig. 4b) with the highest prices obtained by the Biate (median 18,000 INR, 279 USD, per kg, compared with 16,000 INR, 248 USD, for the Karbi and 15,000 INR, 232 USD, per kg for the Dimasa; K-W $\left.\chi^{2}=38.90, \mathrm{DF}=2, p<0.001\right)$. Over half $(59.6 \%, N=84)$ of hunters questioned thought that the scales they sold would be used for medicine (mostly to cure piles; three interviewees also referred to the use of scales to treat "stomach disease" or stomach problems and two to a pendant that a child can wear to "cure vomiting"). Other suggestions as to what buyers might use the scales for included predominantly "protection from termites", good luck charms or amulets or "use in toilet tanks" (Fig. $5 \mathrm{~b}$, further explanations in figure legend). Fifteen percent $(N=22)$ of hunters did not know what the scales would be used for, only that someone was willing to buy them.

\section{Attitudes towards pangolins and perceived population trends}

When asked how they felt about pangolins (on a scale of 1 to 5 , with 1 being strongly dislike and 5 strongly like), there was a strong bias towards liking pangolins, with $61.7 \%(N=87)$ of interviewees reporting that they strongly liked pangolins, $29.8 \%$ 


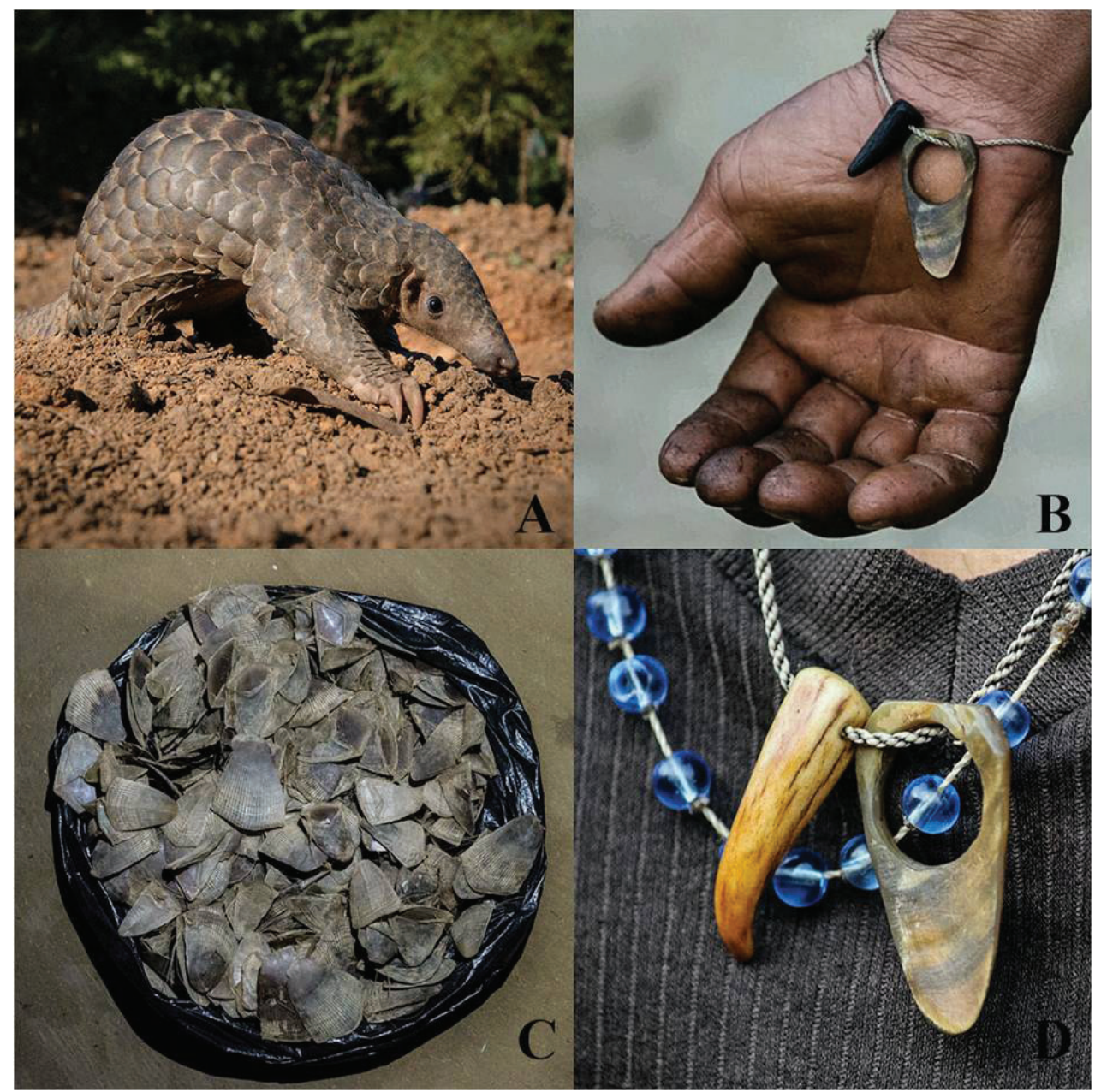

Figure 6.A Indian pangolin (Manis crassicaudata) B Pangolin scale worn as a charm bracelet $\mathbf{C}$ a bag of pangolin scales intended for commercial sale D Pangolin scale and claw worn as talisman. Dima Hasao district, Assam.

$(N=42)$ quite liking them and none disliking them (nine said "neither like nor dislike", two did not answer the question and one said he did not know). The majority [63.8\% $(N=90)]$ of interviewees said that the benefits provided by pangolins (to either themselves or to the forest) were "income from trade". Other benefits suggested were: medicinal benefits $(N=8)$, provision of a food source $(N=4)$, good luck $(N=5)$, killing termites or protecting trees from termites $(N=10)$, creating holes for other animals to live or shelter in $(N=7)$ and that they were considered "harmless" (to humans, animals, agricultural fields and the forest, $N=5$ ). Seven interviewees said that pangolins provided no benefits (but also no disbenefits). Most interviewees [88.7\% $(N=125)$ ] believed that there were fewer pangolins than there were five years ago (although they were not asked why they thought this to be the case). 
Of 105 hunters who described a memorable experience associated with hunting or catching a pangolin, some $(N=30)$ reported that hunting pangolins was always hard work, "hard labour" or "difficult" and described how they might have to dig all day or dig a hole over $2 \mathrm{~m}$ deep, whereas others $(N=33)$ seemed to have come across pangolins opportunistically (e.g. in the road, from where they could simply pick them up) or said that they caught them easily (e.g. by finding them in a log and "easily" taking them out or by setting a trap near the den hole). Twenty referred to being "lucky", "happy" or it being a "good day", when they captured the pangolin (or captured a particularly large pangolin). One interviewee said that it was "the happiest moment of [his] own life" when he caught a "big" (3 kg) pangolin and three others (two of whom appeared to hunt together) remarked that it was like "winning the lottery". Very few interviewees revealed precisely why it was a particularly good day when they caught a pangolin or what they needed the income for, except for two who referred to covering their debts and two others who said they used the money to pay for medical treatment for their family.

\section{Discussion}

Our study represents the first socio-economic review of pangolin poaching being carried out by three of the tribal groups in Assam, Northeast India. Our approach permitted extensive data to be collected and provides a unique insight into the practices, drivers and impacts associated with this type of wildlife trade activity. Our findings clearly demonstrate that male rural hunters, belonging to the Biate, Dimasa and Karbi tribes in Dima Hasao district, are carrying out pangolin hunting, both for personal and commercial gain. The fact that more than 100 interviewees stated that they have hunted pangolins during the past twelve months (and captured at least one in the last five years) indicates that such activity is likely to be commonly practised by hunters of these communities throughout the district of Dima Hasao.

\section{Why are rural hunters targeting pangolins in Assam?}

The local use of pangolin derivatives in India is "steeped in tradition" and it is therefore unsurprising that, during our field study, hunters listed a number of medicinal and superstitious uses for both pangolin meat and scales that broadly reflected those previously described by Mohapatra et al. (2015). However, unlike some findings made elsewhere [e.g. Myanmar (Nijman et al. 2016)] the results of our study indicate that, broadly speaking, hunters in Dima Hasao are not currently targeting pangolins specifically for their meat. For example, with regards to personal use, only a minority of hunters reported using pangolin meat for medicinal purposes. Furthermore, although all hunters said that they ate the meat if they caught a pangolin, the fact that most disliked it (or ranked it very low compared with other bush meat) suggests that they ate it only because they could not afford not to. This was reflected in the stated prices obtained 
for pangolin meat [being less valuable than other types of domesticated meat sold in Dima Hasao e.g. chicken (approx. 200 INR, 3.1 USD, per kg) and goat approx. (450 INR, 7.0 USD, per kg)]. With regards to commercial use, although pangolin meat is a luxury product in China and Vietnam (Challender et al. 2015), hunters provided little indication that the meat was traded beyond the local area.

In contrast to pangolin meat, it is apparent from our study that rural hunters in Dima Hasao are specifically targeting pangolins for their scales and that commercial gain has supplanted traditional use as the primary driver for this type of activity. Specifically, hunter responses overwhelmingly indicate that, while relatively few might use some of the pangolin scales obtained from a hunt themselves, they actually go on to sell the vast majority. Unlike pangolin meat, it is likely that the pangolin scales are destined for urban and international consumers. For example, during our study, hunters were more likely to travel to the city to sell the scales and some hunters reported that buyers come from the city to buy scales directly from the rural villages or at local markets. These results are consistent with the study of Thapa et al. (2014) in Eastern Nepal, where pangolins were hunted primarily for trade and used occasionally by local people for food but rarely for traditional medicine. In both cases, hunters, in the context of the illegal wildlife trade, fall into a combined typology of subsistence/opportunistic harvesters (as defined by Phelps et al. 2016). However, similar to Challender (2011), our survey suggests that the external market may now be driving the opportunistic (economic) element of hunting, whilst the (local) subsistence element appears to be of relatively little importance. These types of commercially-motivated opportunistic behaviour, that are neither a primary nor a regular livelihood, are often overlooked in discussions of illegal wildlife trade (Phelps et al. 2016 and references therein).

Interestingly, $15 \%$ of hunters interviewed during our study stated that they did not know precisely what the scales they sold were being used for or why the market existed, rather only that consumers were willing to pay a substantial amount for them (see also Katuwal et al. 2015). An additional 8\% of hunters did not provide any answer at all in this regard. This lack of knowledge on consumer demand amongst rural hunters may explain some of the more perplexing novel answers provided on intended use - for example, the use of pangolin scales to unblock toilet tanks. This also adds weight to concerns that more wealthy urban actors are exploiting rural hunters (see Duffy and St John 2013 and references therein), potentially taking advantage of both their ability to source pangolin scales and their lack of knowledge regarding their use and commercial value.

\section{What is a pangolin worth to a rural hunter in Assam?}

Our study also serves to demonstrate just how economically valuable a pangolin has become to rural hunters in the Dima Hasao district of Assam, India. We found that, on average, hunters capture one pangolin per year, receive an average of 200 INR (3.1 USD) per $\mathrm{kg}$ of meat (which for an approx. $3 \mathrm{~kg}$ animal is $600 \mathrm{INR}$, equivalent to 9.3 USD), plus an average of 17,000 INR per $\mathrm{kg}$ of scales (equivalent to 263 USD per $\mathrm{kg}$ of scales at the time of writing). Therefore, assuming that there are ap- 
proximately $0.5 \mathrm{~kg}$ of scales per animal (Zhou et al. 2012), we estimate that hunters can potentially receive up to a total of around 9,000 INR per pangolin (for the meat and scales combined if they do not consume the meat themselves, equivalent to 139 USD). Even when divided by up to five people who might take part in a given hunt, this could amount to 1,800 INR (28 USD) each, in a one-off payment, that is likely to occur once per year. When compared to an average annual income of 25,000 INR (387 USD), this means that a single pangolin may be worth just less than one months' income to a hunter in this area, even when hunting with others. A hunter operating alone has the potential to obtain a far greater amount, closer to just under a full year's income for those on the lowest incomes.

Furthermore, the prices paid for pangolin scales in India are reported to have increased substantially in recent decades. For example, Chinlampianga et al. (2013) reported that scales sold for 1,000 INR per kg in 1996 increased to INR 13,000 per kg in 2012 across different locations in the State of Mizoram. In accordance with increasing value elsewhere (e.g. Zhou et al. 2014, Trageser et al. 2017), the price obtained for scales during our survey in 2017 (taking account of inflation in India over the intervening time period, obtained from http://calculatorstack.com/inflation-calculator-india. php) was ten times that reported by Misra and Hanfee (2000) in 1997-1998 for scales sold at collection points or at trading centres. As such, the potential economic value of a pangolin to a rural hunter is likely to increase further as pangolins become even more rare and demand continues to increase - a phenomenon that has been coined the anthropogenic Allee effect (Courchamp et al. 2006, see also Aisher 2016).

\section{What are the impacts of hunting on pangolins?}

For most hunters interviewed during our study, hunting pangolins, either for their meat and or their scales, did not appear to be a frequent activity. Rather it seemed that they came across pangolins or their signs accidentally and then decided to hunt the animal opportunistically. Alternatively, they only occasionally decided to go into the forest and search for a pangolin. However, the fact that most of the hunters interviewed identified pangolins as being less abundant than they were five years ago suggests that levels of off-take, although seemingly low, are unsustainable. The low reproductive rate of pangolins (one to two young per year, Mahmood et al. 2015, Zhang et al. 2016) is already recognised as a biological factor which makes wild populations particularly vulnerable to any level of hunting (CITES 2017). Furthermore, our study indicates that peak pangolin hunting activity in Dima Hasao took place between the months of March and May. This coincides with the period when female pangolins are reported to have their young [recorded in India as occurring between January and April (Mahmood et al. 2015)] that are also taken by hunters. The practice of destroying burrows, cutting down or burning hollow trees to capture pangolins may also have additional conservation impacts by reducing the availability of denning habitat (Newton et al. 2008). As in Mohapatra et al. (2015), we were unable to distinguish between 
pangolin species, but anecdotal reports of black and red pangolins, suggest that both species were involved.

In addition to conservation concerns, there are a number of animal welfare issues associated with hunting practices currently being applied in Dima Hasao. The duration of suffering is of particular concern given that hunters stated it can take several hours to successfully extricate a pangolin from its burrow or tree den during capture. Live transport after capture is also of concern (see e.g. Baker et al. 2013). Although we found no evidence of traditional or commercial use of live pangolins, hunters reported that pangolins are often carried in a bag until they reach a more suitable place for subsequent slaughter. The opportunity for animal suffering during slaughter is particularly apparent given that hunters reported placing pangolins into boiling water [a technique employed to aid scale removal (Mohapatra et al. 2015)]. Although 74\% of hunters reported that a knife or club was used to kill the pangolins beforehand, concerns remain that a proportion may still be alive when the boiling process begins.

\section{How can we protect pangolins and people?}

We did not detect any particular demographic characteristics that appeared to dictate either hunting frequency or success, nor did we detect any particular differences amongst the three tribal communities (except for the small differences detected in the prices obtained for pangolin scales). There was also no evidence that individuals with lower incomes were more likely to resort to hunting pangolins. However, it is important to note that all rural hunters in this area can be considered to receive relatively low incomes and the monetary rewards that could be gained from capturing a pangolin and selling its scales were substantial relative to income. Furthermore, some comments and memorable experiences described by hunters anecdotally suggested that the money received was needed for necessities (medical treatment, schools) rather than for luxuries or to "get rich".

Our study also serves as another useful case study which exemplifies the extent to which unsustainable consumer demand for pangolin scales and associated illegal trade activity can permeate remote rural communities involving many individuals who, most likely, do not fully understand the true ramifications of demand or even why the market exists (CBD - Subsidiary Body on Scientific, Technical and Technological Advice 2016).

\section{What are the limitations of our study?}

Caution is almost always required in interpreting data derived from hunter interviews, particularly when hunting involves some element of illegality (e.g. Newton et al. 2008). Given the sensitive nature of the information asked for in our surveys, interviewees might have been reluctant to be honest about the magnitude of illegal hunting activi- 
ties and there is a risk that the data underestimate the impact of hunting. However, our aim was not to assess the extent of impact or the total number of people involved, rather we sought to understand the practices undertaken by those who were willing to admit that they hunted pangolins and their reasons for doing so. That over a hundred hunters were willing to talk to us and that almost all (those who sold the meat or scales) openly admitted to an illegal activity, suggests that they were being truthful (at least insofar as hunting one pangolin is as illegal as hunting several, so there is little reason not to be honest about the details). The overall similarity in the answers from hunters across 31 different villages (that might be up to $50 \mathrm{~km}$ from one another) in interviews carried out over a year, further suggests that the data are reliable.

\section{Conclusion}

The information that we obtained from hunters in this study was consistent with respect to existing knowledge of the pangolin trade (e.g. Mohapatra et al. 2015). However, it also provides new information that can help to further inform about existing and future initiatives to better protect pangolins and people being exploited by consumer demand for the most "trafficked mammal in the world". Our results suggested that commercial gain has supplanted traditional use as the primary driver for pangolin hunting, specifically as related to the use of pangolin scales. Pangolin meat was clearly only consumed or sold as a by-product of this activity and there was no evidence that it entered trade beyond perhaps sale within the hunters' village. That the value of pangolin scales from a single animal approximates to four months' of the average income of hunters in this region illustrates the substantial financial gains that are possible, even when hunting pangolins only occasionally. For this reason, whilst interventions to reduce poverty are no doubt required (Challender and MacMillan 2014), we suspect that such interventions alone are unlikely to be effective in reducing illegal and unsustainable wildlife trade in Dima Hasao. Rather, co-ordinated packages of mutually reinforcing interventions are required to address illegal and unsustainable wildlife trade in a more comprehensive manner (TRAFFIC 2008, Mohapatra et al. 2015). In particular, we agree with Challender et al. (2014a; see also Verissimo et al. 2012) that implementing a demand reduction strategy targeting urban consumers (particularly in China and Vietnam) is also crucial for addressing the welfare and conservation crisis facing pangolins, especially given that there is some encouraging evidence that similar reduction campaigns for other species have been successful (Cheng et al. 2017). Given that all hunters whom we interviewed seemed to hunt pangolins occasionally, regardless of tribe, demography or income, we suggest that any mitigation strategy should focus on all rural hunters in this region.

\section{Acknowledgements}

This research project was fully funded by World Animal Protection. We sincerely thank all field assistants (who elected to remain anonymous). 


\section{References}

Aisher A (2016) Scarcity, Alterity and Value: Decline of the Pangolin, the World's Most Trafficked Mammal. Conservation \& Society 14(4): 317-329. https://doi.org/10.4103/09724923.197610

Aiyadurai A (2011) Wildlife hunting and conservation in Northeast India: A need for an interdisciplinary understanding. International Journal of Galliformes Conservation 2: 61-73.

Babbie E (2004) The Practice of Social Research (10 $\left.{ }^{\text {th }} \mathrm{edn}\right)$. Thomson/Wadsworth, Belmont.

Baker SE, Cain R, van Kesteren F, Zommers ZA, D’Cruze N, Macdonald DW (2013) Rough Trade: Animal Welfare in the Global Wildlife Trade. Bioscience 63(12): 928-938. https:// doi.org/10.1525/bio.2013.63.12.6

Baillie J, Challender D, Kaspal P, Khatiwada A, Mohapatra R, Nash H (2014) Manis crassicaudata. The IUCN Red List of Threatened Species 2014: e.T12761A45221874. http:// dx.doi.org/10.2305/IUCN.UK.2014-2.RLTS.T12761A45221874.en

Betlu ALS (2013) Indigenous knowledge of zootherapeutic use among the Biate tribe of Dima Hasao District, Assam, Northeastern India. Journal of Ethnobiology and Ethnomedicine 9(1): 56. https://doi.org/10.1186/1746-4269-9-56

Boakye MK, Pietersen DW, Kotzé A, Dalton D-L, Jansen R (2015) Knowledge and uses of African pangolins as a source of traditional medicine in Ghana. PLoS One 10(1): e0117199. https://doi.org/10.1371/journal.pone.0117199

Boakye MK, Pietersen DW, Kotzé A, Dalton D-L, Jansen R (2014) Ethnomedicinal use of African pangolins by traditional medical practitioners in Sierra Leone. Journal of Ethnobiology and Ethnomedicine 10(1): 76. https://doi.org/10.1186/1746-4269-10-76

BSA [British Sociological Association] (2017) Statement of Ethical Practice. BSA Publications www.britsoc.co.uk/media/24310/bsa_statement_of_ethical_practice.pdf

CBD [Subsidiary Body on Scientific Technical and Technological advice] (2016) Beyond enforcement: involving indigenous peoples and local communities in combating illegal wildlife trade: regional workshop for West and Central Africa. Twentieth meeting Montreal, Canada, 25-30 April 2016 UNEP/CBD/SBSTTA/20/INF/59. https:/www.cbd.int/doc/ meetings/sbstta/sbstta-20/information/sbstta-20-inf-59-en.pdf

Census of India (2011) 2011 Census Data. Office of the Registrar General \& Census Commissioner, India, Ministry of Home Affairs, Government of India. Available from: http:// censusindia.gov.in/2011-Common/CensusData2011.html

Challender DWS (2011) Asian pangolins: Increasing affluence driving hunting pressure. Traffic Bulletin 23(3): 92-93.

Challender DWS, MacMillan DC (2014) Poaching is more than an Enforcement Problem. Conservation Letters 7(5): 484-494. https://doi.org/10.1111/conl.12082

Challender DWS, Hywood I (2012) African pangolins - under increased pressure from poaching and intercontinental trade. Traffic Bulletin 24(2): 53-55.

Challender DWS, Harrop SR, MacMillen DC (2015) Understanding markets to conserve trade-threatened species in CITES. Biological Conservation 187: 240-259. https://doi. org/10.1016/j.biocon.2015.04.015

Challender D, Baillie J, Ades G, Kaspal P, Chan B, Khatiwada A, Xu L, Chin S, KC R, Nash H, Hsieh H (2014b) Manis pentadactyla. The IUCN Red List of Threatened Spe- 
cies 2014: e.T12764A45222544. http://dx.doi.org/10.2305/IUCN.UK.2014-2.RLTS. T12764A45222544.en

Challender DWS, Waterman C, Baillie JEM (2014a) Scaling up pangolin conservation. IUCN SSC Pangolin Specialist Group Conservation Action Plan. Zoological Society of London, London.

Cheng W, Xing S, Bonebrake TC (2017) Recent Pangolin Seizures in China Reveal Priority Areas for Intervention. Conservation Letters 10(6): 757-764. https://doi.org/10.1111/ conl.12339

Chinlampianga M, Singh RK, Sukla AC (2013) Ethnozoological diversity of Northeast India: Emperical learning with traditional knowledge holders of Mizoram and Arunachal Pradesh. Indian Journal of Traditional Knowledge 12(1): 18-30.

Choudhary AN, Badola S, Fernandes M, Chhabra DB (2018) TRAFFIC Factsheet. Pangolins 2018. TRAFFIC India, New Delhi.

Choudhury A (2013) The mammals of North East India. Gibbon Books and the Rhino Foundation for nature in NE India, Guwahati.

CITES (2017) Consideration of proposals for amendment of Appendices I and II. Seventeenth meeting of the Conference of the Parties, Johannesburg (South Africa), 24 September - 5 October 2016. https://cites.org/eng/cop/17/prop/index.php

Courchamp F, Angulo E, Rivalan P, Hall RJ, Signoret L, Bull L, Meinard Y (2006) Rarity Value and Species Extinction: The Anthropogenic Allee Effect. PLoS Biology 4(12): e415. https://doi.org/10.1371/journal.pbio.0040415

Duffy R, St John FAV (2013) Poverty, poaching and trafficking: what are the links? Evidence on demand. UK DFID. http://dx.doi.org/10.12774/eod_hd059.jun2013.duffy

Duffy R, St John FA, Büscher B, Brockington D (2016) Toward a new understanding of the links between poverty and illegal wildlife hunting. Conservation Biology 30(1): 14-22. https://doi.org/10.1111/cobi.12622

Fife D (2017) Fifer: A Biostatisticians Toolbox for Various Activities, Including Plotting, Data Cleanup, and Data Analysis. R package version 1.1. https:/CRAN.R-project.org/ package $=$ fifer

Gomez L, Leupen BTC, Krishnasamy K, Heinrich S (2017) Scaly nexus: mapping Indonesian pangolin seizures (2010-2015). TRAFFIC, Southeast Asia Regional Office, Petaling Jaya, Selangor.

Gomez L, Leupen BTC, Hwa TK (2016) The trade of African pangolins to Asia: A brief case study of pangolin shipments from Nigeria. Traffic Bulletin 28: 3-5.

Government of India (2007) The Constitution of India. Government of India, New Delhi. https://www.india.gov.in/my-government/constitution-india/constitution-india-full-text

Harrington LA, D'Cruze N, Macdonald DW (2018) Rise to fame: events. media activity and public interest in pangolins and pangolin trade, 2005-2016. Nature Conservation.

Heinrich S, Wittman TA, Ross JV, Shepherd CR, Challender DWS, Cassey P (2017) The global trafficking of pangolins: a comprehensive summary of seizures and trafficking routes from 2010 to 2015. TRAFFIC Southeast Asia, Petaling Jaya, Selangor, Malaysia.

Heinrich S, Wittmann TA, Prowse TAA, Ross JV, Delean S, Shepherd CR, Cassey P (2016) Where did all the pangolins go? International CITES trade in pangolin species. Global Ecology and Conservation 8: 241-253. https://doi.org/10.1016/j.gecco.2016.09.007 
Ingram DJ, Coad L, Abernethy KA, Maisels F, Stokes EJ, Bobo KS, Breuer T, Gandiwa E, Ghiurghi A, Greengrass E, Holmern T, Kamgaing TOW, Ndong Obiang A-M, Poulsen JR, Schleicher J, Nielsen MR, Solly H, Vath CL, Waltert M, Whitham CEL, Wilkie DS, Scharlemann JPW (2017) Assessing Africa-wide pangolin exploitation by scaling local data. Conservation Letters 11(2): e12389. https://doi.org/10.1111/conl.12389

Katuwal HB, Neupane KR, Adhikari D, Sharma M, Thapa S (2015) Pangolins in eastern Nepal: Trade and ethno-medicinal importance. Journal of Threatened Taxa 7(9): 7563-7567. https://doi.org/10.11609/JoTT.o4202.7563-7

Ma J-E, Li L-M, Jiang H-Y, Zhang X-J, Li J, Li G-Y, Yuan L-H, Wu J, Chen J-P (2017) Transcriptomic analysis identifies genes and pathways related to myrmecophagy in the Malayan pangolin (Manis javanica). PeerJ 5: e4140. https://doi.org/10.7717/peerj.4140

Mahmood T, Kanwal K, Zaman IU (2018) Records of the Indian Pangolin (Mammalia: Pholidota: Manidae: Manis crassicaudata) from Mansehra District, Pakistan. Journal of Threatened Taxa 10(2): 11254-11261. https://doi.org/10.11609/jott.3314.10.2.11254-11261

Mahmood T, Akrim F, Irshad N, Hussain R, Fatima H, Andleeb S, Aihetasham A (2017) Distribution and illegal killing of the endangered Indian pangolin Manis crassicaudata on the Potohar Plateau, Pakistan. Oryx 2017: 1-6. https://doi.org/10.1017/S0030605317000023

Mahmood T, Irshad N, Hussain R, Akrim F, Hussain I, Anwar M, Rais M, Nadeem MS (2015) Breeding habits of the Indian pangolin (Manis crassicaudata) in Potohar Plateau, Pakistan. Mammalia 80(2): 231-234. https://doi.org/10.1515/mammalia-2014-0153

Mahmood T, Irshad N, Hussain R (2014) Habitat Preference and Population Estimates of Indian Pangolin (Manis crassicaudata) in District Chakwal of Potohar Plateau, Pakistan. Russian Journal of Ecology 45(1): 70-75. https://doi.org/10.1134/S1067413614010081

Mahmood T, Hussain R, Ishrad N, Akrim F, Nadeem MS (2012) Illegal mass killing of Indian pangolin (Manis crassicaudata) in Potohar region, Pakistan. Pakistan Journal of Zoology 44: 1457-1461.

Mambeya MM, Baker F, Momboua BR, Pambo AFK, Hega M et al. (2018) The emergence of a commercial trade in pangolins from Gabon. African Journal of Ecology 56(3): 601-609. https://doi.org/10.1111/aje.12507

Misra M, Hanfee F (2000) Pangolin distribution and trade in East and Northeast India. TRAFFIC Dispatches 14 (June 2000).

Mohapatra RK, Panda S (2014) Behavioural descriptions of Indian pangolins (Manis crassicaudata) in captivity. International Journal of Zoology 2014: 795062. https://doi. org/10.1155/2014/795062

Mohapatra RK, Panda S, Nair MV, Acharjyo LN, Challender DWS (2015) A note on the illegal trade and use of pangolin body parts in India. Traffic Bulletin 27(1): 33-40.

Nash HC, Wong MHG, Turvey ST (2016) Using local ecological knowledge to determine status and threats of the critically endangered Chinese pangolin (Manis pentadactyla) in Hainan, China. Biological Conservation 196: 189-195. https://doi.org/10.1016/j.biocon.2016.02.025

Newing H (2011) Conducting research in conservation: a social science perspective. Routledge, Abingdon, Oxford. https://doi.org/10.4324/9780203846452

Newton P, Van Thai N, Roberton S, Bell D (2008) Pangolins in peril: Using local hunters' knowledge to conserve elusive species in Vietnam. Endangered Species Research 6: 41-53. https://doi.org/10.3354/esr00127 
Nijman V (2015) Pangolin seizures data reported. Traffic Bulletin 27(2): 44-46.

Nijman V, Zhang MX, Shepherd CR (2016) Pangolin trade in the Mong La wildlife market and the role of Myanmar in the smuggling of pangolins into China. Global Ecology and Conservation 5: 118-126. https://doi.org/10.1016/j.gecco.2015.12.003

Pantel S, Anak NA (2010) A preliminary assessment of pangolin trade in Sabah. TRAFFIC Southeast Asia, Petaling Jaya, Malaysia.

Pantel S, Chin SY (2008) Proceedings of the Workshop on Trade and Conservation of Pangolins Native to South and Southeast Asia. 30 June - 2 July 2008, Singapore Zoo, Singapore. TRAFFIC Southeast Asia, Petaling Jaya, Selangor, Malaysia.

Phelps J, Biggs D, Webb EL (2016) Tools and terms for understanding illegal wildlife trade. Frontiers in Ecology and the Environment 14(9): 479-489. https://doi.org/10.1002/fee.1325

Potgieter GC, Weise FJ, Wachter B, Melzheimer J, Wiesel I, Stratford K (2017) Comment on Rust et al.: Human-Carnivore Conflict in Namibia Is Not Simply About Black and White. Society \& Natural Resources 30(10): 1299-1303. https://doi.org/10.1080/08941920.20 17.1283077

R Core Team (2017) R: A language and environment for statistical computing. R Foundation for Statistical Computing, Vienna. https://www.R-project.org

Sajem AL, Gosai K (2006) Traditional use of medicinal plants by the Jaintia tribes in North Cachar Hills district of Assam, northeast India. Journal of Ethnobiology and Ethnomedicine 2: 33. https://doi.org/10.1186/1746-4269-2-33

Sajem AL, Gosai K (2010) Ethnobotanical investigations among the Lushai tribes in North Cachar Hills district of Assam, North East India. Indian Journal of Traditional Knowledge 9(1): 108-113.

Soewu DA, Adekanola TA (2011) Traditional-medical knowledge and perception of pangolins (Manis spp.) among the Awori people, southwestern Nigeria. Journal of Ethnobiology and Ethnomedicine 7(1): 25. https://doi.org/10.1186/1746-4269-7-25

Soewu DA, Ayodele IA (2009) Utilisation of pangolin (Manis sps) in traditional Yorubic medicine in Ijebu province, Ogun State, Nigeria. Journal of Ethnobiology and Ethnomedicine 5(1): 39. https://doi.org/10.1186/1746-4269-5-39

Soewu DA, Sodeinde OA (2015) Utilization of pangolins in Africa: Fuelling factors, diversity of uses and sustainability. International Journal of Biodeversity and Conservation 7(1): 1-10. https://doi.org/10.5897/IJBC2014.0760

St. John FAV, Brockington D, Bunnefeld N, Duffy R, Homewood K, Jones JPG, Keane AM, Milner-Gulland EJ, Nuno A, Razafimanahaka JH (2016) Research ethics: Assuring anonymity at the individual level may not be sufficient to protect research participants from harm. Biological Conservation 196: 208-209. https://doi.org/10.1016/j.biocon.2016.01.025

Sutter JD (2014) The most trafficked animal you've never heard of. CNN: Change the list. http://edition.cnn.com/interactive/2014/04/opinion/sutter-change-the-list-pangolin-trafficking/ [Accessed $11^{\text {th }}$ Jan 2018]

Teronpi V, Singh HT, Tamuli AK, Teron R (2012) Ethnozoology of the Karbis of Assam, India: Use of ichthyofauna in traditional health-care practices. Ancient Science of Life 32(2): 99-103. https://doi.org/10.4103/0257-7941.118547 
Thapa P, Khatiwada AP, Nepali SC, Paudel S (2014) Distribution and conservation status of Chinese pangolin (Manis pentadactyla) in Nangkholyang VDC, Taplejung, Eastern Nepal. American Journal of Zoological Research 2(1): 16-21.

TRAFFIC (2008) What's driving the wildlife trade? A review of expert opinion on economic and social drivers of the wildlife trade and trade control efforts in Cambodia, Indonesia, Lao PDR and Vietnam. East Asia and Pacific Region Sustainable Development Discussion Papers. East Asia and Pacific Region Sustainable Development Department, World Bank, Washington DC.

Trageser SJ, Ghose A, Faisai M, Mro P, Mro P, Rahman SC (2017) Pangolin distribution and conservation status in Bangladesh. PLoS One 12(4): e0175450. https://doi.org/10.1371/ journal.pone.0175450

Verissimo D, Challender DWS, Nijman V (2012) Wildlife trade in Asia: Start with the consumer. Asian Journal of Conservation Biology 1(2): 49-50.

Xu L, Guan J, Lau W, Xiao Y (2016) An overview of pangolin trade in China. TRAFFIC Briefing Paper (September 2016). TRAFFIC, Cambridge, UK

Zhang F, Wu S, Zou C, Wang Q, Li S, Sun R (2016) A note on captive breeding and reproductive parameters of the Chinese pangolin, Manis pentadactyla Linnaeus, 1758. ZooKeys 618: 129-144. https://doi.org/10.3897/zookeys.618.8886

Zhang M, Gouveia A, Qin T, Quan R, Nijman V (2017) Illegal pangolin trade in northernmost Myanmar and its links to India and China. Global Ecology and Conservation 10: 23-31. https://doi.org/10.1016/j.gecco.2017.01.006

Zhou Z-M, Zhou Y, Newman C, Macdonald DW (2014) Scaling up pangolin protection in China. Frontiers in Ecology and the Environment 12(2): 97-98. https://doi. org/10.1890/14.WB.001

Zhou Z-M, Zhao H, Zhang Z-X, Wang Z-H, Wang H (2012) Allometry of scales in Chinese pangolins (Manis pentadactyla) and Malayan pangolins (Manis javanica) and application in judicial expertise. Zoological Research 33(3): 271-275. http://www.zoores.ac.cn/EN/ Y2012/V33/I3/271. https://doi.org/10.3724/SP.J.1141.2012.03271

\section{Supplementary material I}

\section{Hunter questionnaire}

Authors: Neil D’Cruze, Bhagat Singh, Aniruddha Mookerjee, Lauren A. Harrington, David W. Macdonald

Data type: form

Explanation note: English translation of questions asked and information recorded. Copyright notice: This dataset is made available under the Open Database License (http://opendatacommons.org/licenses/odbl/1.0/). The Open Database License $(\mathrm{ODbL})$ is a license agreement intended to allow users to freely share, modify, and use this Dataset while maintaining this same freedom for others, provided that the original source and author(s) are credited.

Link: https://doi.org/10.3897/natureconservation.30.27379.suppl1 